cooling from a magma near the surface. It would be much simpler to estimate polythionates in waters than to determine sulphur dioxide in fumarole gases, and this estimation might be a useful way of judging the activity of an area, or following changes in activity with time.

Dominion Laboratory,

Department of Scientific and

Industrial Research, Wellington,

New Zealand.

${ }^{2}$ Mitchell, A. D., and Ward, A. M., "Modern Methods in Quantitstive Chemical Analysis" (Ĺondon: Longmans, Green and Co., Ltd., 1932).

' Maclaurin, J. S., Proc. Chem. Soc., 27, 10 (1911).

- Kurtenacker, A., "Analytische Chemie der Sauerstoffsäuren des Schwefels"' (Stuttgart: F. Fnke, 1938).

- Doy, A. L., and Allen, E. T., "The Volcanic Activity and Hot Springs of Lassen Peak" (Washington : Carnegie Institution 1925).

- Wilson, S.H., N.Z.J. Sci. \& Tech., 20, 246 (1939).

\section{Flow of Air through Rocks at Low Rates}

DurINa routine measurements of the permeability of rocks carried out in 1939-40, certain anomalies were observed when the rate of flow was extremely low. It was seen that when the rock was highly impervious and the velocity of the flowing air was consequently low due to limitations in the pressure, a plot of the pressure loss $v$. rate of flow did not yield a straight line passing through the origin. 'Darcy's law having been established with such rigour by many workers before, however, necessitated the rejection of the anomalous results as due to "experimental errors". The same type of anomalies, however, were again observed recently in measuring the permeability of other samples. Thus, it was decided that the phenomenon be investigated, after having first refined and adapted the apparatus for measurements at extremely low rates of flow.

Fig. I shows the results on one sample which was subjected to the test. The ordinate is the product of $\bar{Q}$, the rate of flow at mean pressure, $\left(P_{1}+P_{2}\right) / 2$, where $P_{1}$ and $P_{2}$ are inlet and outlet pressures in atmospheres, and $\mu$ the viscosity of the air at the temperature of observation, divided by the crosssectional area of the sample, $A$. The abscissa is the differential pressure across the sample $\left(P_{1}-P_{2}\right)$ divided by the length of the sample, $\tilde{L}$. It is seen that at low rates of flow, or low differential pressures, the graph is a curve and not a straight line.

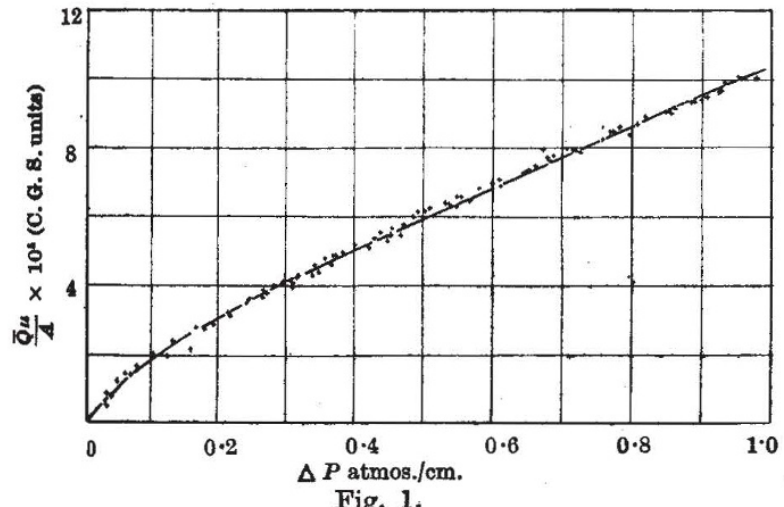

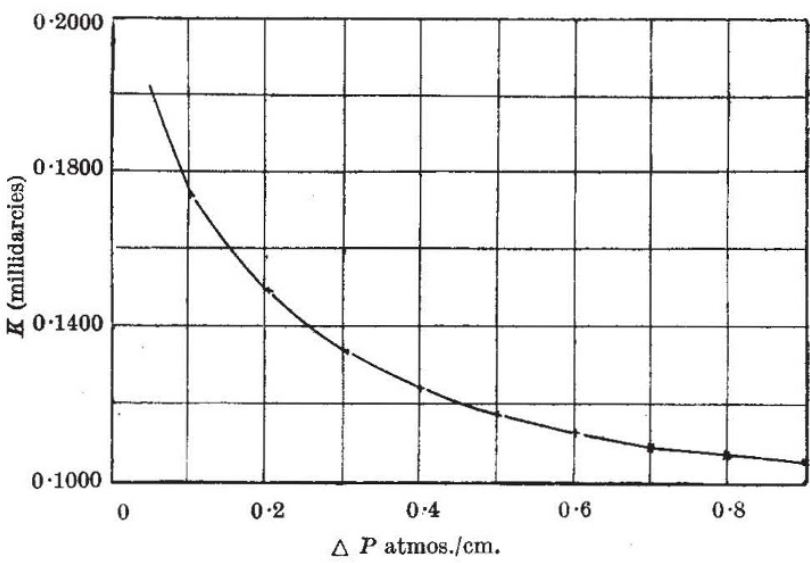

Fig. 2.

Fig. 2 shows the results in another form. The permeability, which is the tangent at each point of graph on Fig. 1, is plotted against the pressure differential. It is seen that instead of the constant value for permeability demanded by Darey's law, a variable permeability is obtained, falling to an assymptotic value at higher rates of flow. The assymptotic value is what is usually obtained in permeability measurements using fairly high rates but necessarily limited to the viscous regime.

The possibility of turbulence is completely excluded by the nature of the tests, by the fact that at higher rates of flow in Fig. 1 the curve straightens out into. the normal viscous regime curve, except for the anomaly that it does not pass through the origin exactly, and further by the fact that the region where the graph curves does not follow the equation

$$
\Delta p=a v+b v^{2} .
$$

Other tests reveal the fact that the permeability value first increases to a maximum, after which it descends in value until it reaches the assymptotic value indicated.

Full description of the experiments will be published later in another place.

Department of Oil Engineering

A. H. NIssan. and Refining,

University,

Birmingham, 15.

Sept. 18.

\section{The Philosophy of Physical Science}

Sir Arthur Eddington has not met my point (Nature, Sept. 20, p. 341). Assuming, in accordance with his claim, that criteria could exist which would determine that a law was applicable to certain experiences, I asked what he would do if such experiences were found to violate an "inviolable" law. He has related what Adams and Leverrier did when experience afforded an opportunity of testing a law not held to be inviolable. My question still remains.

I agree that if a law appears to be broken, the physicist asks whether a factor has been overlooked. $\mathrm{He}$ also reviews his calculations to look for errors, repeats his observations to make sure he was not 